\title{
Impact of COVID-19 on agricultural markets: assessing the roles of commodity characteristics, disease caseload and market reforms
}

\author{
Deepak Varshney $^{1} \cdot$ Devesh Roy $^{1} \cdot$ J. V. Meenakshi ${ }^{2}$
}

Published online: 24 August 2020

(C) Editorial Office, Indian Economic Review 2020

\begin{abstract}
This paper assesses the impact of the spread of COVID-19 and the lockdown on wholesale prices and quantities traded in agricultural markets. We compare whether these impacts differ across non-perishable (wheat) and perishable commodities (tomato and onion), and the extent to which any adverse impacts are mitigated by the adoption of a greater number of agricultural market reform measures. We use a granular data set comprising daily observations for 3 months from nearly 1000 markets across five states and use a double- and triple- difference estimation strategy. Expectedly, our results differ by type of commodity and period of analysis. While all prices spiked initially in April, they recovered relatively quickly, underscoring the importance of time duration for analysis. Wheat prices were anchored in large part by the minimum support price, while tomato prices were lower in some months. Supply constraints began easing in May with greater market arrivals perhaps reflecting distress sales. Market reform measures did help in insulating farmers from lower prices, but these effects are salient for the perishable goods, and not so much for wheat where the government remained the dominant market player. Taken together, these results point to considerable resilience in agricultural markets in dealing with the COVID-19 shock, buffered by adequate policy support.
\end{abstract}

Keywords COVID-19 - Wholesale prices and trade $\cdot$ Market reforms · Government policy

JEL Classification $\mathrm{O} 13 \cdot \mathrm{Q} 02 \cdot \mathrm{Q} 18 \cdot \mathrm{L} 78$

J. V. Meenakshi

meena@econdse.org

1 South Asia Region, International Food Policy Research Institute, New Delhi, India

2 Department of Economics, Delhi School of Economics, University of Delhi, Delhi, India 


\section{Introduction}

There is no gainsaying the fact that in addition to its impact on public health, COVID-19 and the lockdown that was undertaken beginning in March 2020 in an attempt to contain its spread have had a major economic impact that has affected all sectors of the economy. The agricultural sector and agricultural markets are no exception. Unlike many other countries, the agricultural sector in India accounts for $60 \%$ of all rural employment and is thus the single largest source of livelihoods.

Notwithstanding the fact that food comes under the ambit of essential commodities that in principle are exempt from movement restrictions, India's food markets have been significantly impacted by the spread of the novel coronavirus (and COVID-19 disease). The impact has manifested itself in the form of demand as well as supply shocks. The employment and income shocks that translated into an across-the-board demand compression have been further exacerbated by the closure of hotels, restaurants, and institutions. Also, consumers' buying behaviour has changed, with greater online transactions and home-delivery services displacing inperson purchases and restaurant meals. Produce growers and distributors are being forced to shift supplies from food service outlets to retail channels. On the supply side, all across the value chain, there are labour and logistical constraints. All these factors have implications for the quantities of goods that arrive at the wholesale markets that feed retail outlets, and the prices at which trade occurs.

While these effects of the COVID-19 crisis are not unique to India (see for example, Chetty et al. 2020), they are likely magnified. This is because agricultural markets in India, unlike in more developed countries, are heavily dependent on cash transactions. Also, cash flow constraints are more salient in agricultural markets than in other sectors of the Indian economy. Partly as a consequence, throughout the value chain, growers, traders, and retailers, accustomed to traditional methods of stocking and choosing suitable inventory management mechanisms, do not have built-in systems to deal with such disruption. Indeed, with COVID-19, they face shocks in both supply and demand of an order of magnitude never seen before in Indian markets, arguably exceeding that faced during the 2016 episode of demonetization.

Of particular concern is the primary commodity end of the value chain. For instance, a record wheat harvest was anticipated (Business Standard, February 18, 2020), and the lockdown coincided with peak harvest times. It is conceivable that the pandemic would affect availability of labour for harvest, even though the return of urban migrants to their rural homes may have eased this constraint. COVID-19 and lockdowns could also affect the transport of grain and, as a consequence, prices that farmers receive. Although the government responded with urgency in opening trade in agricultural commodities (these were the first set of exemptions to lockdown measures), this alone may not have been enough to provide sufficient cash in the system for agricultural markets to function.

It is in this context that we attempt to assess the impact of the spread of COVID19 and the lockdown. We review the nature of changes in the functioning of agricultural markets and assess the net impact on (a) prices and (b) arrivals of commodities 
at wholesale markets. These impacts may be viewed as net consequences of behavioural responses from consumers, wholesalers, and retailers through to farmers. Farm incomes are by their very nature seasonal, and prices and quantities traded of commodities whose harvest times begin from late March are a key determinant of the liquidity of farmers, and how their livelihoods are being affected by the pandemic.

We consider markets in five major wheat-producing states: Uttar Pradesh, Madhya Pradesh, Rajasthan, Punjab, and Haryana. We compare whether the short-term, immediate impact on prices of wheat (non-perishable, easier for farmers to store and tide over periods of depressed prices) differed from that on two perishable commodities, tomato and onion (absent cold storage, limited ability of farmers to time sales). We also assess if states that had undertaken a greater degree of market reforms were better able to protect farmers from disruption. Additional details are provided below.

The empirical evidence on the impact of the pandemic on food and agricultural markets is still emerging. For instance, Mahajan and Tomar (2020) find that there was a drop of $10 \%$ in the online availability of various foods (with no impact on retail prices) in the immediate aftermath of the first lockdown. There was also a drop of nearly $20 \%$ in market arrivals of vegetables and fruits in a few cities between March and April. They attribute these largely to supply-chain disruptions. Narayanan and Saha (2020), analysing retail and wholesale prices through the end of April, find that for many commodities, including pulses and edible oils, among others, prices witnessed a sharp spike immediately after the lockdown. They find that movement restrictions acted to limit arbitrage possibilities across cities and contributed to increased spread in prices.

Our paper contributes to this literature in several ways. First, the analysis extends the period of post-lockdown coverage to the end of June: as seen later, this distinction between the immediate (within a month) versus short-term (over 3 months) matters to the analysis. Second, we consider a wider geography of nearly 1000 markets across five states with daily price observations for 91 days across 2 years, 2019 and 2020. Third, we use the spread of COVID-19 (using data on caseloads in each district), as distinct from the lockdown itself, to identify differential impacts. Fourth, we compare whether these effects differed across non-perishable and perishable crops. Fifth, we explicitly examine the role of government policy-specifically, procurement and agricultural market reforms - in mitigating any adverse impacts in terms of holding the markets. We focus in particular on the delisting of fruits and vegetables as part of the reform package. We believe this is the first attempt to quantify these effects, and to focus both on procurement and agricultural market reform interventions.

We restrict our attention to three crops. As mentioned earlier, the wheat harvest was to take place during the lockdown, with over 107 million tons of harvest (up from 103.6 million tons from last year) potentially at stake. The five states included in this paper account for over $80 \%$ of national cropped area in wheat. They together have over 44 million farmers. Apart from the non-perishable nature of wheat and its status as a principal cereal, there is another reason to focus on it. Except for Rajasthan and the eastern part of Uttar Pradesh, there is active 
government involvement in procurement operations-either by the Food Corporation of India or by decentralized systems at the state level.

The five states also account for a sizeable share of the acreage under cultivation of the two other crops, onion (20\% of national cropped area) and tomato $(17 \%)$. These two vegetables rank second and third in terms of area under vegetable cultivation nationwide (potato has the highest area, but a bulk of the harvest in these states was completed before the lockdown began). While tomato and onions are not subject to government procurement, we examine what impact, if any, agricultural market reforms in the form of deregulation, had on market outcomes.

In the empirical analysis, we first consider the COVID-19 caseload at market locations and its association with prices and quantities traded-the expectation is that market outcomes will be impacted more in areas with higher caseloads as people either voluntarily self-quarantine, or there are cases detected in the markets leading to temporary shutdowns, or because restrictions are enforced more stringently.

Next, we look at outcomes differentiated by the degree of regulatory reforms adopted by states. The first generation of agricultural market reforms was introduced in 2003 through a model Agriculture Produce Marketing Committee (APMC) act. More recently in 2017, an Agriculture Produce and Livestock Marketing Act (APLMA) was introduced with an aim to rebuild appropriate market infrastructure for the public and private sectors to benefit both farmers and consumers. As agriculture is a state subject in India, states could embark on and adopt various provisions of the APLMA to suit their local conditions with the driving spirit being the welfare of farmers.

Different states have adopted these reforms to varying degrees. A priori, locations in states with a greater implementation of market reforms should see lower variation in the form of collapse or volatility in outcomes at the margin. In principle, by expanding choices available to various participants in the value chain, the APLMA reforms should attenuate any crashes or spirals in quantities and prices in markets induced by the pandemic and lockdown, and also moderate the extent of changes in prices and market arrivals. In the case of fruits and vegetables, in most states, the earlier APMC act prohibited sales outside of notified market yards. In states where these commodities are now delisted from this regulation as recommended by the APLMA, farmers are free to choose to trade with anyone and at any place, including at the farm gate. Delisting also entailed doing away with market fees and intermediary agents' commission (even if the sale took place in a notified mandi). Mishra and Tilton (2019) find that this deregulation played a role in reducing marketing margins, which was then transmitted as lower retail food price inflation.

Apart from short run impacts, there will be longer-term consequences of COVID19 that are likely to persist for not just the entire duration of the pandemic, but longer. This underscores the need to understand the success with which market reform policies can deal with shocks. As such, research on the impact of agricultural market reforms on farmer and market-related outcomes in India is scant. Further, how the effects of shocks are differentiated across markets as a function of reforms remain unknown. This paper uses the COVID-19 shock to assess any differential outcomes across markets with different intensities of reform. 
More generally, the exogenous COVID-19 shock and associated lockdowns provide a natural setting for assessing differences in impacts based on product, market, and institutional characteristics in agricultural markets. We compare market outcomes in 2020 to the immediate past in 2019 in day-on-day (d-o-d) comparisons to isolate any market differences that are not in line with the normal drift.

To estimate the causal impact of the pandemic and lockdown, we employ a difference-in-difference (DID) estimation by assessing differential outcomes (the treatment effect) between high and low caseload locations. In triple-difference estimation, we additionally invoke the extent to which states had adopted agricultural market reforms to see whether it made any difference to the impacts of COVID-19. The null hypotheses that we test are the following:

(i) Market outcomes in terms of prices and quantities transacted are no different in high versus low COVID caseload locations relative to 2019.

(ii) Prices and quantities were not impacted for a long time and recovered quickly

(iii) Markets in states that implemented more agricultural market reforms did not experience impacts on prices and quantities any different than those in areas with lower tier of reforms.

Our salient results are: first, a spike in prices, wherever it occurred, was concentrated in the first month of the lockdown. Prices fell subsequently, suggesting that markets responded relatively quickly. However, impacts were commodity specific. Wheat saw a trend reduction in prices, but it was no different from a similar period in the previous year, leading to a statistically insignificant differential impact. In large part, this was because of minimum support price (MSP) operations that served to anchor wholesale prices. Among perishable commodities, DID price effects were negative in May for tomato, and insignificant for onion. In contrast, market arrivals, especially of the two perishable goods, were significantly higher in districts with high caseloads, consistent with evidence of sales conducted to generate cash. That the magnitude of (positive) market arrival effects was much larger than that of the (negative) price effects is testimony to the resilience of agricultural markets.

Second, as far as agricultural market reforms are concerned, they did not seem to matter much to wheat prices: a mere $1 \%$ point distinguished differential price effects across high and low COVID caseload districts. This is once again consistent with the anchoring effects of the MSP. In contrast, deregulation effects are clearly discernible for the perishables. Our results suggest that states that delisted fruits and vegetables were able to prevent a decrease in prices by over $10 \%$ points. Market arrivals mirror price effects, with relatively more sales being facilitated for perishables in states that had deregulated their marketing. Taken together, our results find support for a strong, but nuanced role for government policy, both in its procurement and market reform aspects.

The paper is organized as follows. The second section presents a brief description of the coverage of wholesale markets, COVID-19 incidence, and market reforms. The third section presents trends in market arrivals and prices. The fourth section presents the methodology, while the fifth section discusses results, and the sixth ends with conclusions. 


\section{Data}

\subsection{Wholesale markets (mandis) covered}

The data for this paper were downloaded from Government of India's agriculture market information portal, which records daily arrivals and prices at the mandi (wholesale market) level. The database includes information for all 979 mandis across 182 districts (in the five states mentioned above) that trade wheat, tomato, and onion. On average, the sample has an average of five mandis in every district.

\subsection{COVID-19 incidence}

Mandi regime changes in relation to COVID-19 can be mapped into the different phases of lockdown that started from the end of March 2020. Figure 1 presents the distribution of districts by the total number of COVID-19 cases. Among the assessed districts, 35\% had < 100 COVID-19 confirmed cases; $21 \%$ had between 100 and 200 cases; $15 \%$ had 200-300; while $29 \%$ had $>300$ cases. The average per district was 337, indicating the concentrated nature of disease spread. Note that these are recorded cases; the actual caseload is expected to be much higher. However, this under-reporting does not matter for our analysis, unless the extent of under-reporting varies systematically across districts. It is the relative variation between "high" and "low" caseloads that the empirical strategy exploits.

Also, the relaxation of regulations governing movement and economic activity were based largely on the total number of confirmed COVID-19 cases. In fact, the

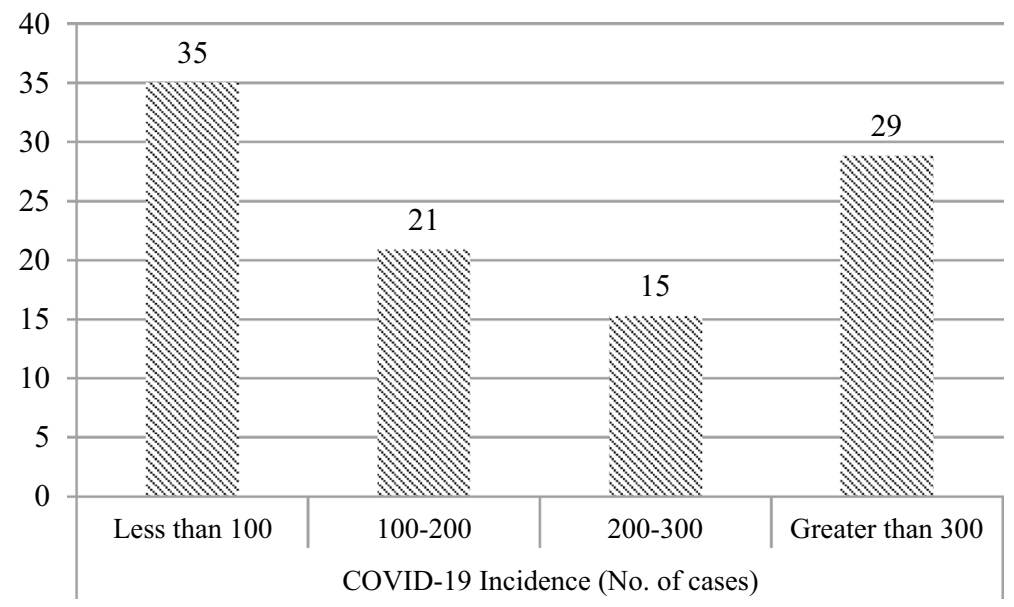

Fig. 1 Distribution of districts by incidence of COVID-19 cases (percent). Source: https://covidindia.org, accessed on 1 July 2020 
government classified districts as green, yellow, and red zones based on recorded positive cases.

Table 1 presents the lockdown and unlock timelines along with delineation of various associated measures. The first period consists of phases 1 and 2 of the lockdown, from 1st April ${ }^{1}$ to 3rd May. Phase 1 consisted of the strictest measures that would have affected activities related to the agricultural sector as well. From phase 2 onwards, there were different levels of relaxations, with exemptions for the agricultural sector being first granted. The second period covers phases 3 and 4 of the lockdown from 4th May to 31st May. In phase 3, further activities were allowed in green districts, with phase 4 allowing for decentralized decision making based on colour-coded zones. The final period was from 1st to 30th June, labelled unlock-1, with an emphasis on re-starting economic activities.

This categorization into periods is important in assessing market dynamics following the COVID-19 shock. If one were to take a short window corresponding to phase 1 of the lockdown, when several markets were indeed closed, the picture would seem to be one of market collapse and sharp price spike, as the studies cited above find. But depending on the scale and stringency of the measures implemented subsequently, agricultural markets did rebound relatively quickly. The speed and extent to which this recovery took place is a function of the type of commodity, COVID-19 caseload and level of market reforms undertaken by state governments.

\subsection{Market reforms}

As noted earlier, the APLMA was introduced in 2017 with a focus on rebuilding market infrastructure for both public and private players. It contained several measures aimed at improving overall welfare, especially of farmers. Uttar Pradesh and Rajasthan each adopted seven provisions of the APLMA. For example, both states adopted single point levy of market fee, single unified trading licence, e-trading, direct marketing, establishment of private markets, and separation of powers and functions amongst administrative functionaries. ${ }^{2}$ Madhya Pradesh, Punjab, and Haryana adopted five provisions each, four of which are common to Madhya Pradesh and Haryana. The details of specific provisions are set out in Table 2.

The analysis uses this information to categorize states into two groups capturing variation in the extent of reforms undertaken. For wheat, the variable is based on the number of provisions of the APLMA that a state adopted. In the case of tomato and onion, the variable captures whether or not a state delisted fruits and vegetables from the purview of a more restrictive earlier APMC regulation.

\footnotetext{
1 The lockdown started on March 25, and our data set begins April 1.

2 Uttar Pradesh also implemented the declaration of warehouses and cold storages as deemed markets, while Rajasthan deregulated the marketing of fruits and vegetables.
} 


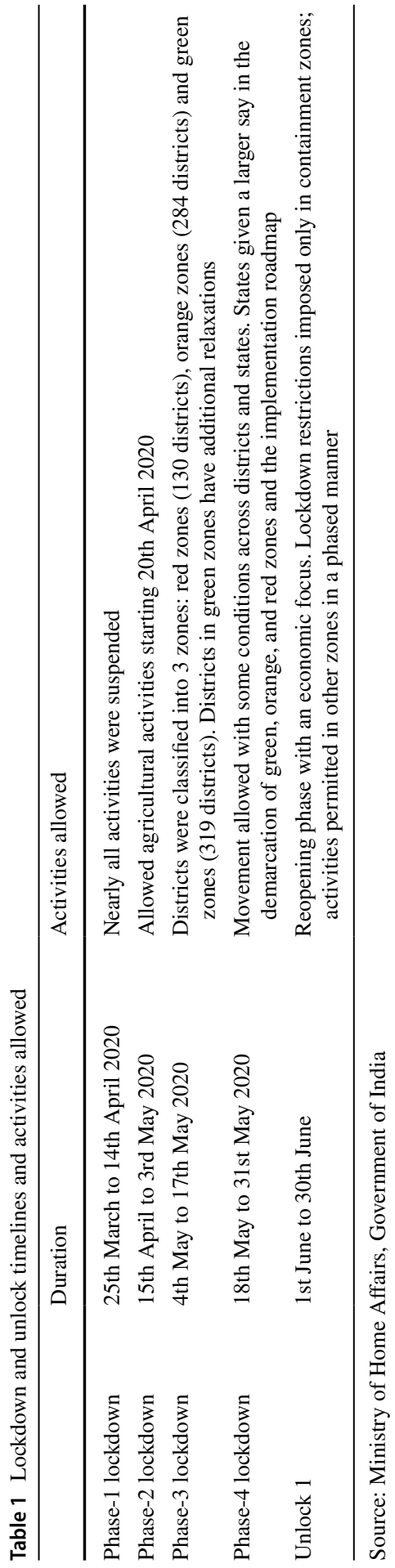


Table 2 Adoption status of APLMA 2017 provisions

\begin{tabular}{ll}
\hline State & Provisions adopted \\
\hline Uttar Pradesh & $\begin{array}{c}\text { Single point levy of market fee, single unified trading licence, E-trading, direct } \\
\text { marketing, private markets, administrative reforms, declaring warehouse/cold } \\
\text { storages as deemed market }\end{array}$ \\
Madhya Pradesh & $\begin{array}{l}\text { Single point levy of market fee, Single unified trading licence, E-trading, direct } \\
\text { marketing, deregulation of marketing of fruits and vegetables }\end{array}$ \\
Rajasthan & $\begin{array}{c}\text { Single point levy of market fee, single unified trading licence, E-trading, direct } \\
\text { marketing, private market, administrative reforms, deregulation of marketing of } \\
\text { fruits and vegetables }\end{array}$ \\
Punjab & $\begin{array}{c}\text { Single point levy of market fee, single unified trading licence, E-trading, direct } \\
\text { marketing, private markets }\end{array}$ \\
Haryana & $\begin{array}{c}\text { Single point levy of market fee, Single unified trading licence, E-trading, direct } \\
\text { marketing, deregulation of marketing of fruits and vegetables }\end{array}$ \\
\hline
\end{tabular}

Source: Niti Aayog (courtesy Professor Ramesh Chand)

\section{Trends in market arrivals and prices}

We compare daily prices and market arrivals for the months of April, May and June across 2019 and 2020. We also use the 2018 data for robustness checks. The price metric used in the analysis is the modal price in each mandi, expressed in real 2020 terms (using monthly wholesale price indices).

For wheat, Fig. 2 shows that the first two phases of the lockdown saw a significant decrease in quantities arriving at the mandis as compared to the previous year. The gap is particularly high during phase 2 which coincided with the peak harvest. During phases 3 and 4 of the lockdown, market arrivals recovered. Possibly due to pent up demand or because farmers who could store wheat stocks could now unload them, unlock-1 saw marginally higher quantities of arrivals as compared to the previous year.

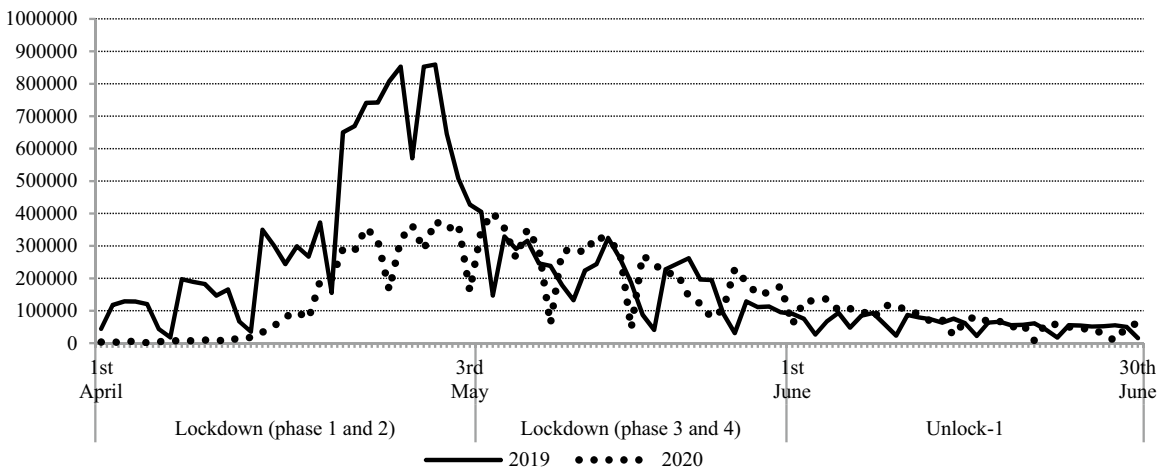

Fig. 2 Wheat arrivals (in tons). Source: https://agmarknet.gov.in/, accessed on 10th July 2020 


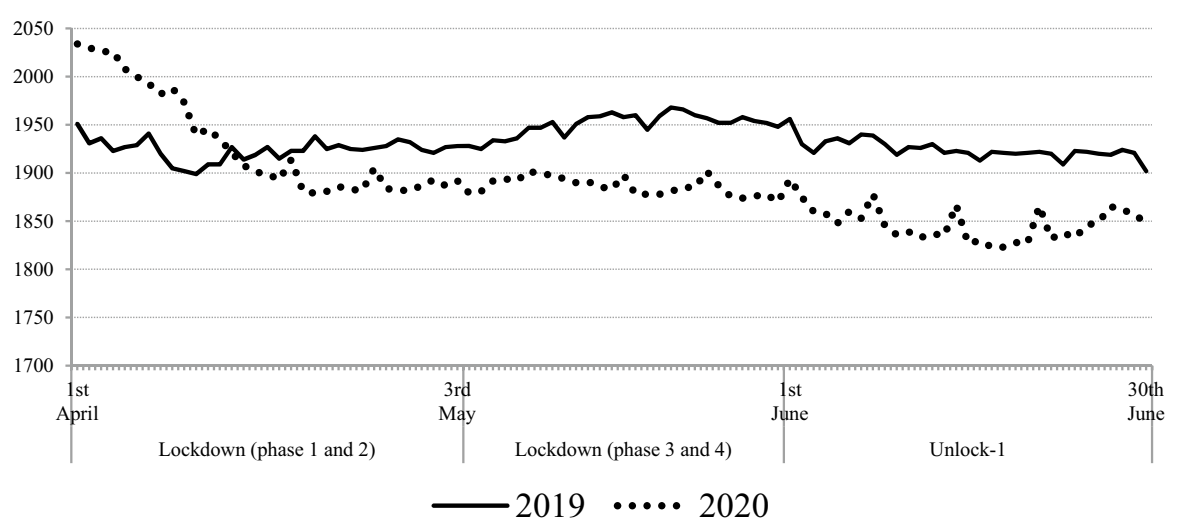

Fig. 3 Wheat price trends (₹ per quintal). Source: https://agmarknet.gov.in/, accessed on 10th July 2020

Mirroring the collapse in market arrivals, prices of wheat (Fig. 3) were significantly higher in phase 1 than in the previous year. In phases 2, 3 and 4, wheat prices were significantly lower compared to 2019 but were for the most part anchored at the MSP. Subsequently in unlock-1 from June onwards, wheat prices decoupled from and trended below the MSP, perhaps in part a reflection of demand compression.

While it is common for procurement operations to be suspended by the end of the marketing season in the end of May, two states, Haryana and Uttar Pradesh, had announced measures to extend procurement operations through the end of June and also offer bonuses for later arrivals. To what extent were these efforts successful? Appendix Fig. 8 shows that these two states were able to maintain the wholesale price at the level of the MSP. In 2019, when procurement operations ceased in the end of May, there was a noticeable drop in wholesale prices, as would be expected when a large player, in this case the government, exits the market. But in 2020, there is no such dip, and prices were maintained largely at the level of the MSP. Thus, the decoupling of the wholesale price from the MSP seen in Fig. 3 was driven largely by price movements in the other three states.

As indicated in Fig. 4, quantities of tomato arriving in the mandis were significantly lower than in the previous year ${ }^{3}$ for both lockdown and unlock-1 phases. Consequently, prices (Fig. 5) were higher, but were trending downward. It is only after 15th June during unlock-1 that prices started increasing and were significantly higher than in the previous year. The period of unlock 1 coincided with unseasonal pre-monsoon rains that affected the prices of all vegetables. It is difficult to disentangle the effect of changes due to the unlock (expected to have pushed up demand) from the weather shock that affected the supply of vegetables.

Figure 6 presents the quantities of onion traded in the mandis each day; during all three periods, market arrivals were significantly lower than in the previous year. They started trending upward in the initial 2 weeks of unlock-1 but again

\footnotetext{
3 We are unable to confirm whether the two spikes in prices noticed in 2019 were data entry errors.
} 


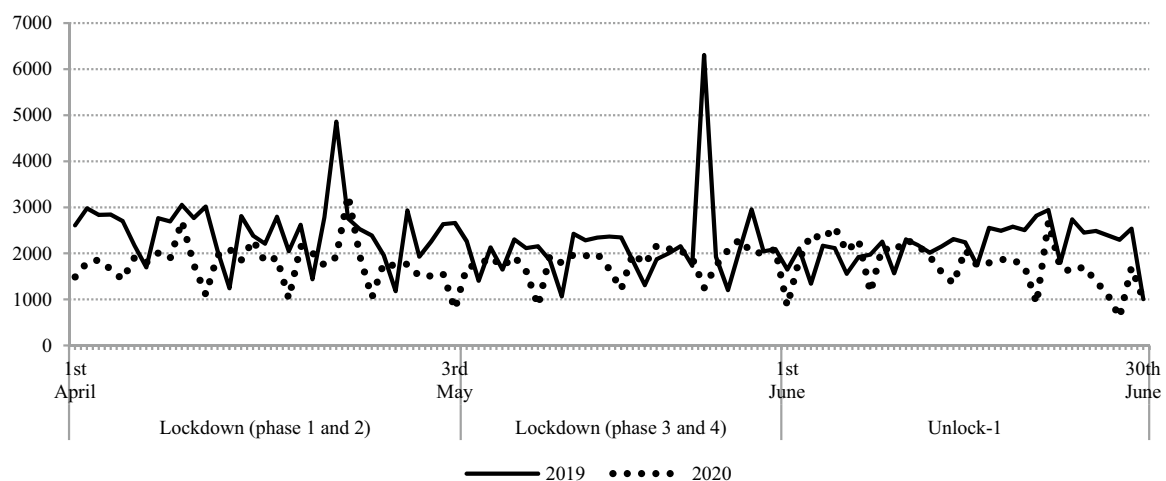

Fig. 4 Tomato arrivals (tons). Source: https://agmarknet.gov.in/, accessed on 10th July 2020

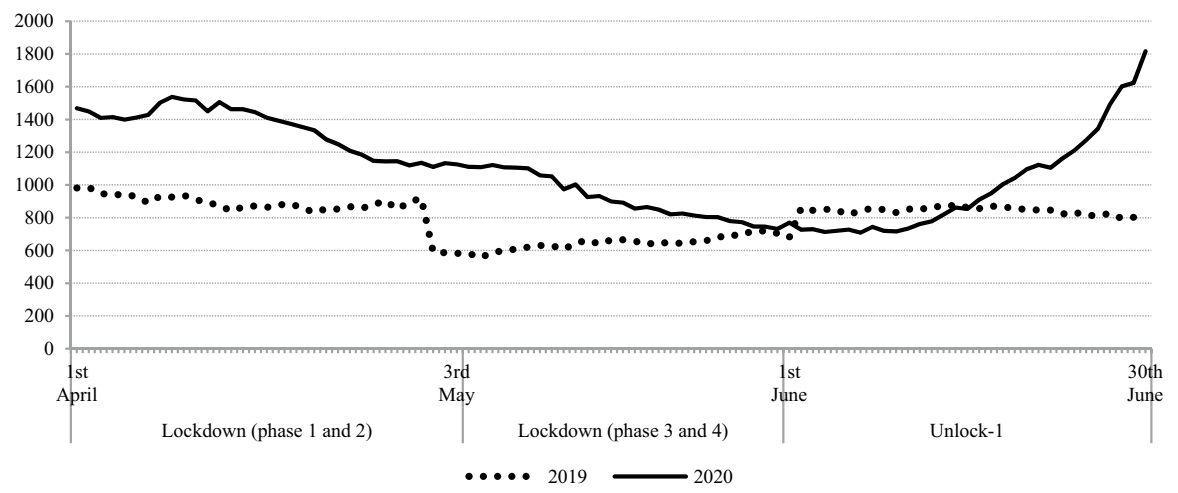

Fig. 5 Tomato price trends (₹ per quintal). Source: https://agmarknet.gov.in/, accessed on 10th July 2020

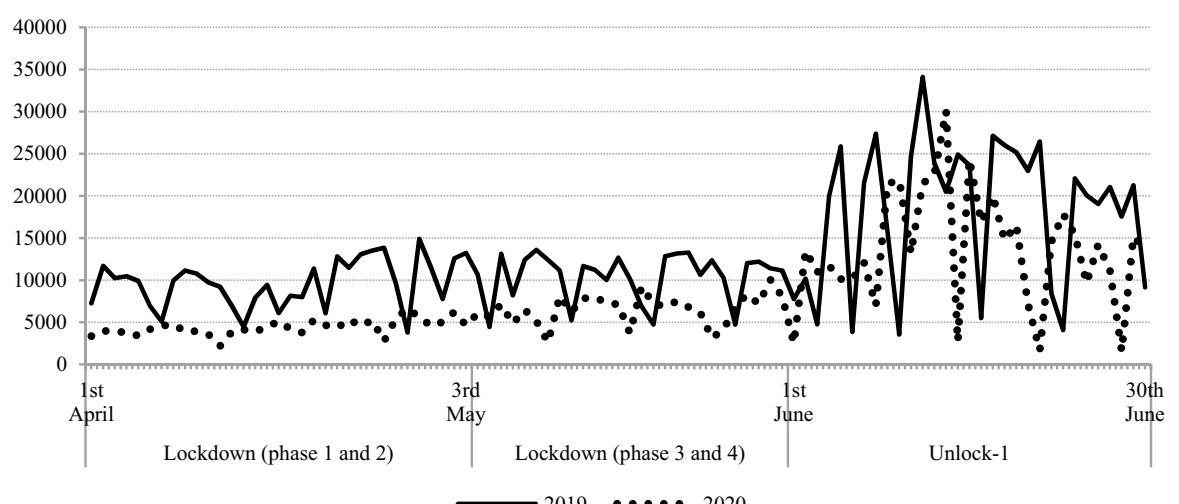

Fig. 6 Onion arrivals (tons). Source: https://agmarknet.gov.in/, accessed on 10th July 2020 


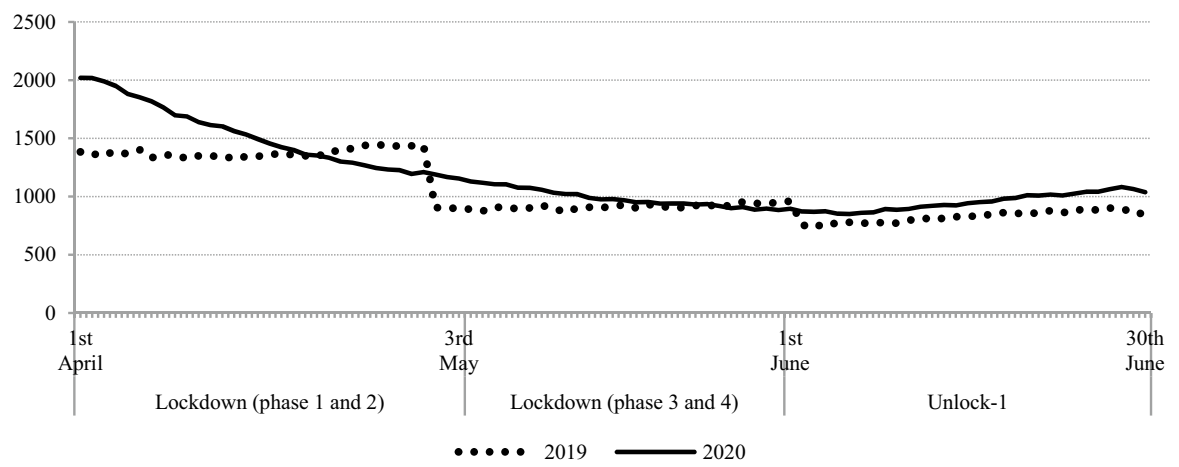

Fig. 7 Onion price trends (₹ per quintal). Source: https://agmarknet.gov.in/, accessed on 10th July 2020

trended downward; day-to-day variability in this unlock period was high. Prices (Fig. 7) were higher therefore in the initial period, but were declining gradually since the start of the first lockdown. There was a modest recovery toward the latter half of the unlock-1 period. Two characteristics of onion are important in relation to the kinetics of price and quantity. The supply of onions is relatively concentrated, but demand is well dispersed. Though supply chain disruptions would have played a role for onions given its concentrated production centres, the demand shock was likely also quite strong with the closure of hotels, restaurants and other food enterprises that use onions more than usual normal household consumption. In addition, there were unsubstantiated reports that consumers perceived poultry to be a source of COVID-19, and hence the poultry sector may also have experienced a concurrent shock. This may have affected the demand for onions that constitute a big part of meat-based food preparations in India.

Further evidence of the disruption in supply chains caused by the pandemic can be seen in the shifts in the distribution of prices between 2019 and 2020. A Kolmogorov-Smirnov test (not presented) indicates that the two sets of price distributions were statistically different for each of the three crops.

\section{Identification strategy}

\subsection{Impact of COVID-19 incidence}

COVID-19 is of course one among many factors leading to differential outcomes in terms of prices and quantities in agricultural markets. There are several confounders such as weather differences, market infrastructure and policy changes. To try and account for these, our identification strategy exploits two important aspects of the data described above. The first is the significant variation in COVID-19 caseloads across districts. The second is the availability of data on prices and quantities for the pre-COVID-19 period on a d-o-d basis. Using variation in COVID-19 caseloads, we classify agricultural markets into two categories: mandis located in districts with (i) 
high COVID-19 incidence versus (ii) low COVID-19 incidence. This enables us to examine whether, after accounting for various confounders (by differencing them out), there are any differences in outcomes in markets across treatment (high COVID incidence districts) and control groups (low COVID incidence districts). Further, we compare changes in outcomes between low and high COVID incidence markets over the period 2019 (pre-COVID-19) and 2020 (COVID-19). Conditional on existence of pre-COVID parallel trends, a standard difference-in-difference impact estimate can be vested with causal interpretation. That is, it is the impact of COVID-19 under the assumption that had the pandemic not occurred, a change in outcomes would not be systematically different in the treatment and control areas.

We estimate the following DID specification:

$$
Y_{\text {idt }}=\alpha_{0}+\alpha_{1}\left([\text { highCovid }]_{\text {idt }} \times \text { time }_{t}\right)+\alpha_{2}[\text { highCovid }]_{\text {idt }}+\alpha_{3}\left(\text { state } \times \text { time }_{\mathrm{t}}\right)+\Omega_{i}+\varepsilon_{\text {idt }},
$$

where $i$ stands for mandi, $d$ for district, and $t$ for year (either 2020 or 2019). $Y$ is daily (subscript suppressed) modal price of wheat, tomato, or onion expressed in real terms. highCOVID is a dummy variable and takes value 1 for markets located in a high COVID caseload district, and equals 0 otherwise. Specifically, highCOVID mandis are located in districts with greater than 100 COVID-19 cases. ${ }^{4}$ As part of robustness checks, we experimented with moving the cutoff for highCOVID from 100 to 200 and then to 300 ; the results are robust. Time is a dummy variable and takes value 1 for the year 2020 and 0 for 2019; $\Omega_{i}$ is the mandi fixed effect and $\varepsilon$ is the error term. All price regressions are weighted by market arrivals. Standard errors are clustered at the week and year levels. ${ }^{5}$ We run the same specification using daily mandi arrivals as the outcome.

The coefficient of interest is $\alpha_{1}$ that identifies the impact of COVID-19 caseload. As a check on the identifying assumption, we re-run specification 1 for the preCOVID-19 years 2018 and 2019. The emerging literature on DID focuses on the need to address why the original levels of the treatment and control groups differed, and uses this to justify impact coefficients. Thus, parallel pre-COVID trends are neither necessary nor sufficient for the comparable counterfactual trends condition to hold (Kahn-Lang and Lang 2020). In this paper, however, we stay with the conventional DID practice of interpreting impacts as causal only upon finding parallel trends (the coefficients are italicized in the tables when this assumption is not met).

We estimate five variants of specification 1. The first is for the month of April (period 1 that covers phases 1 and 2 of lockdown). The second is for the month of

\footnotetext{
${ }^{4}$ We are unable to exploit daily variation in caseloads because of the patchy nature of this data. However, given the exponential nature of the spread of COVID-19, the choice of using caseloads effective June 30 does not matter to the analysis as it exploits variation in high versus low caseload districts; the absolute number of infections does not matter. We acknowledge, however, that this may not completely capture the fact of localized outbreaks as migrants returned from the cities to rural areas.

5 For each crop, year and outcome combination, we conducted a test of the null hypothesis that the series contained a unit root. We were able reject the null hypothesis for 11 of 12 cases, the exception being of tomato prices in 2019. As a further robustness check, both Eqs. 1 and 2 were re-estimated after including date fixed effects; all the results presented here remain robust to this inclusion.
} 
May (sub-period 2 that covers phases 3 and 4). The third is from the month of June coinciding with unlock-1. A fourth variant combines the lockdown months of April and May, while a fifth variant includes the entire period from the months of April to June.

\subsection{Differential impact of market reforms}

As noted earlier, market reforms have not been adopted to the same degree by all states. Based on the extent of adoption of the recommendations of the APLMA, we classify Uttar Pradesh and Rajasthan as states with high intensity of adoption of market reforms, and the remaining as states with low intensity of adoption of market reforms. We study the differential impact of the varying degree of adoption of market reforms across low and high Covid incidence markets, and across time, using a triple difference (TD) framework. Analogous to the DID framework, the TD approach identifies the impact of market reforms if confounding factors are time invariant. We test for these parallel trends using 2018 and 2019 data and provide a causal interpretation to the results only when they are met. We estimate the following triple difference specification.

$$
\begin{aligned}
Y_{\mathrm{idt}}= & \gamma_{0}+\gamma_{1} \text { highCovid }_{\mathrm{idt}}+\gamma_{2} \text { time }_{t}+\gamma_{3} \text { HImarketreform }_{\text {idt }}+ \\
& +\gamma_{4}\left(\text { highCovid }_{\mathrm{idt}} \times \text { time }_{t}\right)+\gamma_{5}\left(\text { highCovid }_{\mathrm{idt}} \times \text { HImarketreform }_{\mathrm{idt}}\right) \\
& +\gamma_{6}\left(\text { HImarketreform }_{\text {idt }} \times \text { time }_{t}\right)+\gamma_{7}\left(\text { highCovid }_{\mathrm{idt}}\right. \\
& \left.\times \text { time }_{t} \times \text { HImarketreform }_{\mathrm{idt}}\right)+\Omega_{i}+\mu_{\mathrm{idt}} .
\end{aligned}
$$

All notation carries over from above, except HImarketreform that takes value 1 if the mandi is in a high intensity market reform state and 0 otherwise. ${ }^{6}$ The coefficient of interest is $\gamma_{7}$ that can be interpreted as the differential impact of COVID incidence in high intensity of reform states. The coefficient $\gamma_{6}$ provides the association of states with higher degree of market reforms in low COVID incidence markets, while $\gamma_{4}$ provides the impact of highCOVID on states with lower degree of market reforms.

We run similar specifications for tomato and onion, except the HImarketreform variable takes value 1 if the state had deregulated the marketing of fruits and vegetables and zero if not.

\section{Results}

\subsection{Impact of COVID-19 incidence}

Table 3 presents DID impact estimates for prices. For wheat (panel A), there was an insignificant impact on prices because of high COVID-19 incidence in the month of April. In May (phases 3 and 4 of lockdown), we find a pre-COVID-19 trend

\footnotetext{
6 There is no confound in the data between high COVID caseload districts and states that adopted more market reforms.
} 


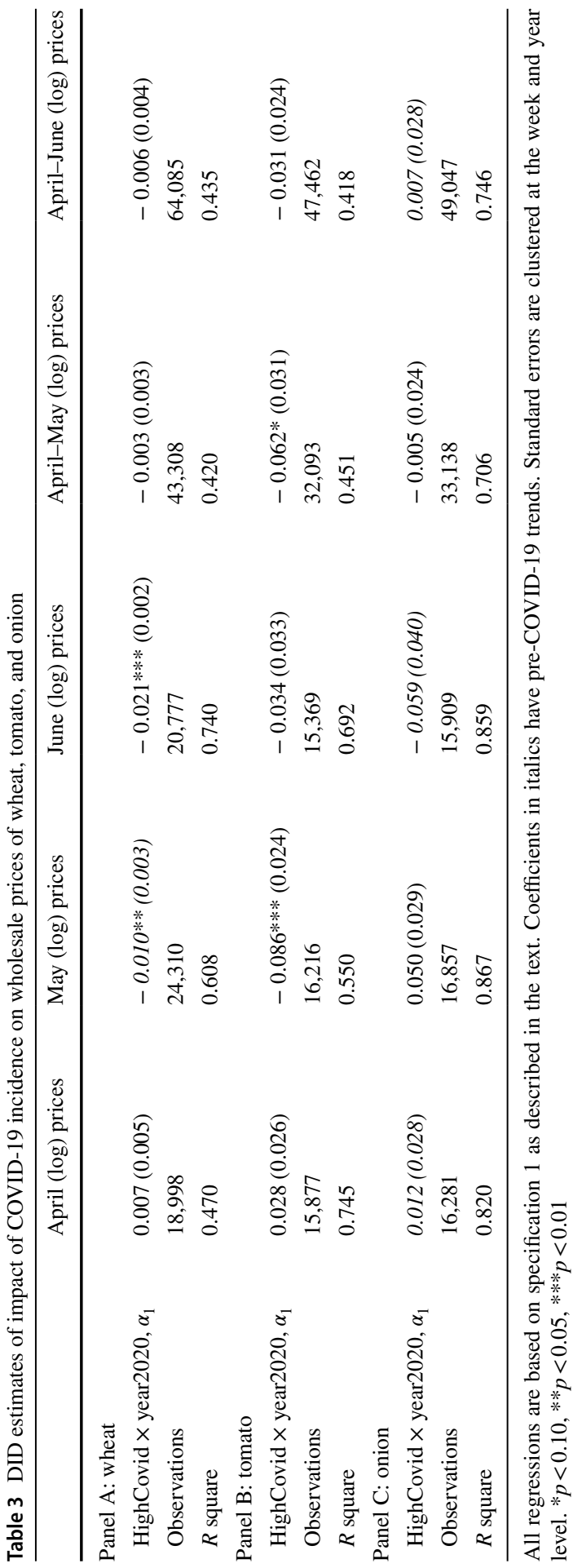


and hence do not interpret the coefficient. But during unlock-1 in June, there was a decline in prices in high COVID markets. The government's decision to provide free rations of $5 \mathrm{~kg}$ of wheat per individual through the Pradhan Mantri Garib Kalyan Yojana by drawing down on public stocks beginning in April may have had a negative effect on the demand for wheat (see for example Varshney et al. 2020). For the entire period of April-June, there was no adverse differential impact on prices- the coefficient is insignificant. This is consistent with the MSP playing an anchoring role in wheat prices.

There was also no statistically significant impact on tomato prices (panel B) in the month of April, but prices did decline in May, so that for the aggregate of April and May, prices in 2020 in high caseload districts registered a modest decline relative to 2019 and relative to low caseload districts. However, by unlock-1 in June, there was some recovery as reflected in an insignificant impact on prices; this was also true of the entire period of April-June. This is contrary to other studies that suggest prices of vegetables increased significantly in the month of May (NCAER, 2020). ${ }^{7}$ For onion (panel C), the impact estimates are either insignificant or not robust to parallel trends for all periods.

Table 4 examines whether these results are largely mirrored by trends in market arrivals. For wheat, while the DID coefficients suggest there was no impact for each of the individual periods, across the 3 months, the magnitude of impact was positive, at $12 \%$. Similarly, the differential impact on quantities traded of tomatoes, depending on the month/period ranged between 25 and 30\%, and for onions, 15 and $20 \%$. Particularly noteworthy are the magnitudes of these coefficients, which suggest that the difference in market arrivals between the same months across 2019 and 2020 was higher in mandis located in high caseload districts than in low caseload districts. Further, the magnitudes are highest for tomato, the most perishable among the three, and least for wheat (non-perishable). This is consistent with farmers seeking to offload stocks given uncertainty or cash constraints. The states considered here are important for onion, but are not the most important producers (Maharashtra, Madhya Pradesh and Karnataka together account for nearly $65 \%$ of the total onion production in India).

\subsection{Differential impact of market reforms}

To what extent did impact differ in states that undertook a greater degree of market reforms? We assess this using a triple difference approach, and focus on the period April-June. Table 5 presents selected coefficients. For wheat, states that adopted a greater degree of market reforms saw $1.2 \%\left(\gamma_{7}\right)$ higher changes in prices as compared to states that had implemented fewer reforms. While statistically significant, the magnitude is small. At the same time, high COVID incidence markets saw an insignificant impact on prices in states with lower degree of market reforms. This is

\footnotetext{
7 This survey also reported that $38 \%$ of surveyed households experienced an increase in prices of grains and pulses in the month of May.
} 


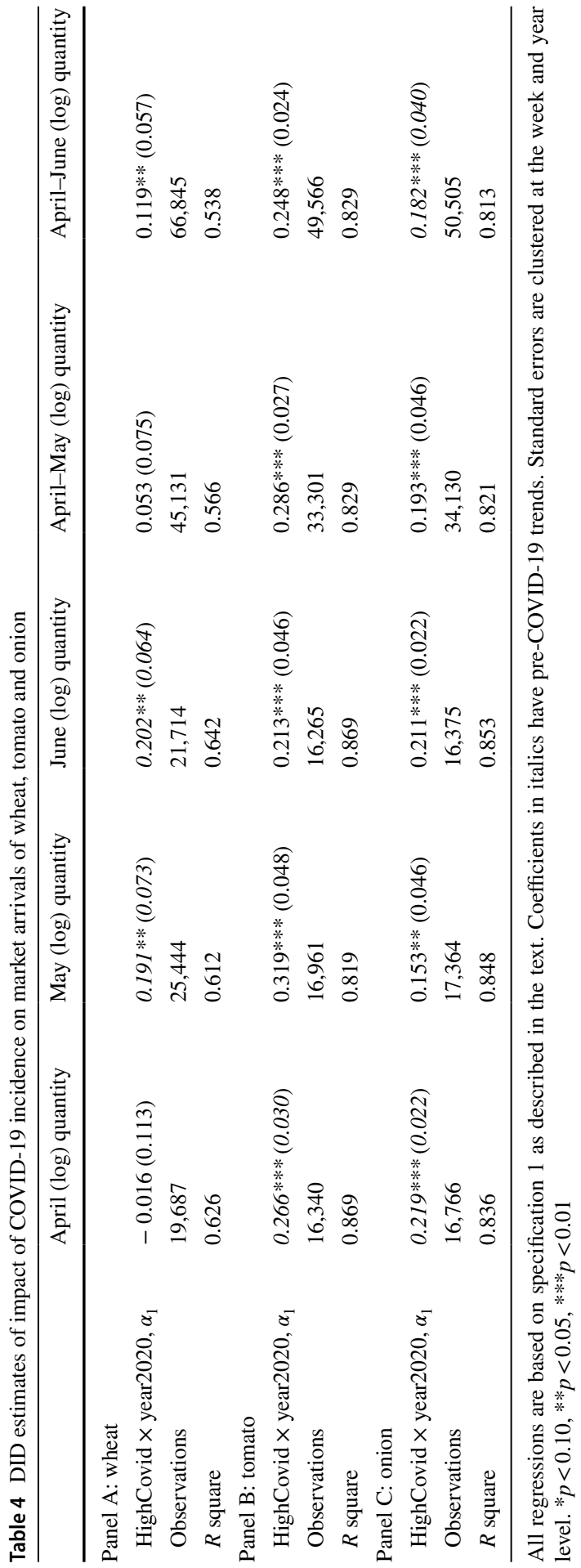


Table 5 Differential (TD) impact of market reform intensity on the prices and market arrivals of wheat

\begin{tabular}{lll}
\hline & Log prices (April-June) & $\begin{array}{l}\text { Log market } \\
\text { arrivals (April- } \\
\text { June) }\end{array}$ \\
\hline HighCovid $\times$ HImarket-reforms $\times$ year2020, $\gamma_{7}$ & $0.012^{* *}(0.005)$ & $-0.245(0.149)$ \\
HImarket-reforms $\times$ year2020, $\gamma_{6}$ & $-0.009 * * *(0.003)$ & $0.055(0.181)$ \\
HighCovid $\times$ year2020, $\gamma_{4}$ & $0.003(0.004)$ & $0.171(0.130)$ \\
Observations & 64,085 & 66,845 \\
$R$ square & 0.417 & 0.535 \\
\hline
\end{tabular}

All regressions are based on specification 2 as described in the text. Coefficients in italics have preCovid-19 trends. Standard errors are clustered at the week and year level. $* p<0.10$, $* * p<0.05$, $* * * p<0.01$

consistent with prices being anchored at the MSP. Market arrival coefficient magnitudes are not robust.

Market reforms had much greater impact on the two perishable goods. In Table 6, the TD coefficient $\gamma_{7}$ suggests that states which adopted more market reforms saw $11.2 \%$ higher difference in tomato prices (panel A). For onion (panel B), the figure is $10.5 \%$. Thus, for these commodities, reforms do seem to have shielded farmers from a higher extent of price collapse. That these effects are statistically significant assumes salience given that for the two perishables, the distinction between low and high intensity of adoption of market reforms was one of deregulation and delisting.

For both tomato and onion, $\gamma_{6}$ is insignificant; that is, states with deregulation of fruits and vegetables were not different from those that did not: market reforms

Table 6 Differential (TD) impact of deregulation of fruits and vegetables on the prices and market arrivals of tomato and onion

Log prices (April-June) Log market arrivals (April-June)

\begin{tabular}{lll}
\hline Panel A: tomato & & \\
HighCovid $\times$ deregulation $\times$ year2020, $\gamma_{7}$ & $0.112^{*}(0.059)$ & $-0.513 * * *(0.061)$ \\
Deregulation $\times$ year2020, $\gamma_{6}$ & $-0.034(0.059)$ & $0.428^{* * *}(0.045)$ \\
HighCovid $\times$ year2020, $\gamma_{4}$ & $-0.067 *(0.028)$ & $0.342^{* * *}(0.027)$ \\
Observations & 47,462 & 49,566 \\
$R$ square & 0.411 & 0.828 \\
Panel B: onion & & \\
HighCovid $\times$ deregulation $\times$ year2020, $\gamma_{7}$ & $0.105^{* *}(0.047)$ & $-0.248^{* *}(0.119)$ \\
Deregulation $\times$ year2020, $\gamma_{6}$ & $-0.096(0.078)$ & $0.149(0.111)$ \\
HighCovid $\times$ year2020, $\gamma_{4}$ & $-0.048 * * *(0.013)$ & $0.265 * * *(0.027)$ \\
Observations & 49,047 & 50,505 \\
$R$ square & 0.745 & 0.813
\end{tabular}

All regressions are based on the specification 2 as described in the text. Coefficients in italics have pre-COVID trends. A Standard errors in the parentheses are clustered by week and year. * $p<0.10$, $* * p<0.05, * * * p<0.01$ 
did not have a role to play in influencing price differences over time in low COVID incidence markets. In a sense this serves as a falsification test, since market reforms were initiated before 2019, and there is no reason to expect a differential impact of these reforms in low COVID caseload mandis. At the same time, for tomato, as expected, prices in high COVID incidence markets were nearly $7 \%$ lower in states which did not undertake high intensity of market reforms relative to those that did (in other words, this is a double difference, conditional on high COVID incidence). For onion, the results are not robust to parallel trends.

The market arrival coefficients are in the expected opposite sign relative to prices and, as before, are of much higher magnitudes than those associated with prices.

\section{Conclusions}

The pandemic is still unfolding all across the country, and its economic consequences are still to be fully apprehended. As such, this paper necessarily has a short (3 month) focus. All our conclusions should be interpreted in this light.

That said, this paper is probably one of the first to estimate the causal impacts of COVID-19 on food prices. In general, if the tenure of market price and quantity changes and the shortness in duration for mean reversal in these outcomes were to be a marker for resilience, it can be said that agricultural markets in India have been quite supple in face of the COVID-19 shock. We find that COVID-19 and its associated disruptions had a differentiated impact—both across commodities and over time. Although all three commodities saw a positive impact coefficient for wholesale prices in April, these were either insignificant, not robust to parallel trends, or both. Wheat saw a decrease in price differentials in June, but the overall impact across the 3 months was insignificant. This is likely because government procurement operations helped anchor wheat prices at the MSP. This continued through June in the two states that extended their period of procurement.

Prices for tomatoes fell in May, but there was no statistically robust impact otherwise. Also, onion prices were unaffected-this may reflect the concentrated nature of its supply, and the relatively dispersed nature of its demand. It is worth reiterating that the five states considered here are not major suppliers of onion; it is likely that there were significant disruptions in supplying markets in Maharashtra, Madhya Pradesh and Karnataka, which account for two-thirds of its production. Additionally, government efforts to support demand through various stimulus provisions may have borne fruit (although we have no way of quantifying this) in limiting the extent of decline or arresting falling wholesale prices.

In comparison, all the market arrival impact magnitudes were positive and significant, especially for the two perishable goods. That the magnitudes of differentials in market arrivals were much higher than those in prices is suggestive (but not conclusive) evidence that supply constraints began easing beginning in May. In the case of the perishables, the positive coefficients on market arrivals may well be a reflection of distress sales and/or the need to address cash flow constraints. Together, these results suggest that while there were undoubtedly short-term disruptions in 
agricultural markets, they were also relatively resilient, in the sense that market arrivals were quick to recover after the initial month, and that possible distress sales did not result in a disproportionate fall in prices.

Assessing the extent of supply chain disruptions attributable to COVID-19unmatched in recent times even by the demonetisation episode-is important from the perspective of public policy (Inoue and Todo 2020). Reardon et al. (2020) comment that the COVID-19 response in India should consist of the government enabling markets to function better and rely less on extensive emergency measures. Our analysis suggests that a more nuanced stance is necessary. The findings indicate a major role for government intervention in two fundamental ways. In cereals, where the government is a major buyer through procurement at MSP, it played an important role in keeping the supply chain intact, and helped mitigate price risk. There is of course an active debate about whether the government should be involved in the physical handling of grain in support operations, how efficiently it does so, and on whether the cereal-focussed nature of government procurement continues to be relevant. This paper is not the forum for engaging in this debate. Suffice it to say, the fact that wheat prices were anchored at the MSP for the better part of 2 months and even later through June in the two states that extended the period of procurement, undoubtedly helped livelihoods for millions of wheat cultivators by mitigating the decrease in prices they might otherwise have faced. Despite their low and declining shares of agricultural value added and the consumer's budget, cereals are cultivated on vast areas and are the single largest source of consumers' caloric intakes. With wheat, what in normal times would be a price support, worked as an insurance (and perhaps even as a stimulus) to the agriculture sector during this pandemic. Procurement is likely to also have ameliorated concerns of cash flow, critical to the functioning of agricultural markets.

The second fundamental way in which policies play a mitigating role relates to agricultural market reforms. States where markets are less restricted did better in managing price volatility; where the distinction for perishables was based simply on whether fruits and vegetables were deregulated and delisted. Market reforms that expand options for both buyers and sellers are certainly needed, as these enable the better absorption of shocks such as COVID-19. But the extent of market reform cannot be judged by the number of regulations alone; there needs to be commensurate investment in infrastructure to help farmers mitigate the effects of such unprecedented shocks. This cannot happen overnight and will require a sustained focus, investment, and creative ways of engaging with market intermediaries all across the value chain.

Acknowledgements We are grateful to Abhijit Banerji and Shreekant Gupta for helpful comments. The usual disclaimer applies.

\section{Appendix}

See Fig. 8 . 


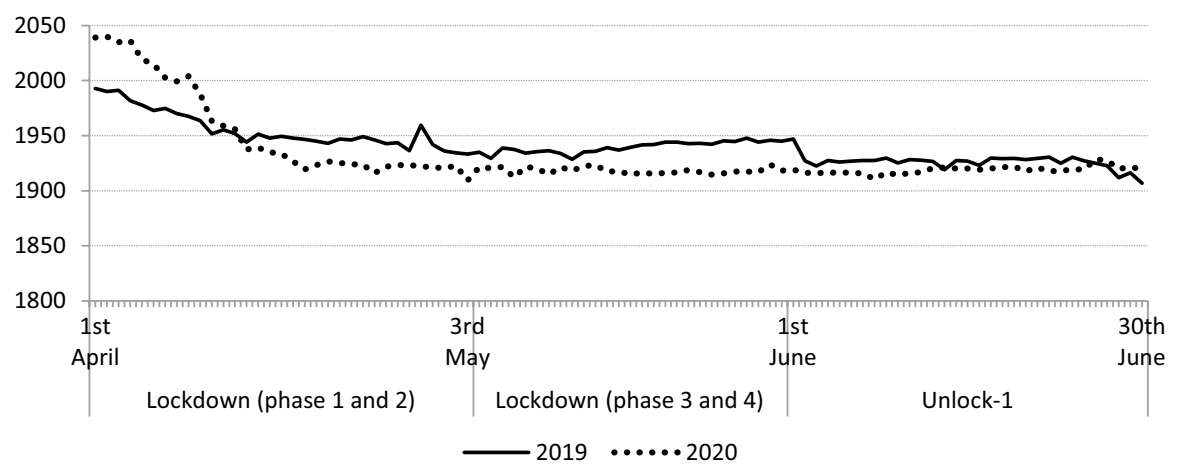

Fig. 8 Wheat price trends in Uttar Pradesh and Haryana (₹ per quintal)

\section{References}

Chetty, R., Friedman, J. N., Hendren, N., \& Stepner, M. (2020). How did COVID-19 and stabilization policies affect spending and employment? A new real-time economic tracker based on private sector data. Working Paper No. 27431, National Bureau of Economic Research

Inoue, H., \& Todo, Y. (2020). The propagation of the economic impact through supply chains: The case of a mega-city lockdown against the spread of COVID-19. Available at SSRN 3564898

Kahn-Lang, A., \& Lang, K. (2020). The promise and pitfalls of differences-in-differences: Reflections on 16 and pregnant and other applications. Journal of Business and Economic Statistics, 38(3), 613-620.

Mahajan, K., \& Tomar, S. (2020). Here today, gone tomorrow: COVID-19 and supply chain disruption. Working Paper No. 28, Ashoka University, Department of Economics

Mishra, P. \& Tilton, A. (2019). Indian food price inflation: Low for long. Goldman Sachs Economics Research

Narayanan, S., \& Saha, S. (2020). Urban food markets and the lockdown in India. Working Paper No. 2020-017, Indira Gandhi Institute of Development Research

NCAER (2020). Delhi NCR coronavirus telephone survey-round 3, preliminary findings, July 4. https:// www.ncaer.org/uploads/photogallery/files/1594022410NCAER_DCVTS3_Presentation.pdf

Reardon, T., Mishra, A., Nuthalapati, C. S., Bellemare, M. F., \& Zilberman, D. (2020). COVID-19's disruption of India's transformed food supply chains. Economic and Political Weekly, 55(18), 18-22.

Varshney, D., Kumar, A., \& Joshi, P. K. (2020). Situation assessment of the rural economy amid COVID19 crisis: Evidence from India. IFPRI South Asia July 23. https://southasia.ifpri.info/2020/07/23/ situation-assessment-of-the-rural-economy-amid-covid-19-crisis-evidence-from-india/

Publisher's Note Springer Nature remains neutral with regard to jurisdictional claims in published maps and institutional affiliations. 